\title{
An Enhanced Phase locked loop with demodulation of FM signals
}

\author{
*Pathan Mohd Basha khan and **Pathan Mohd Aziz khan \\ * JJT University, Rajasthan \\ **JJT University, Rajasthan
}

\begin{abstract}
In this paper present a phase locked loop (PLL) system used in commercial applications because of their low cost. Phase locked loop used to track the phase and the frequency of the carrier component of an incoming signal. This paper discusses about the implementation of PLL device and also presents the VCO, phase comparator and Loop Filter based through demodulation of FM signal. $P L L$ is beneficial device for the demodulation of angle modulated signals, especially when signal to noise ratio is poor and improve the threshold properties also.

Index Terms - Phase locked loop, Voltage controlled oscillator, Frequency Modulating frequency, Low Pass filter, Phase error.
\end{abstract}

\section{I.INTRODUCTION}

PLL is a negative feedback system which performs tracking of phase and frequency components from the input carrier signal. PLL is used now -a-days in commercial FM receivers, because of their low cost and superior performance. A PLL Circuit diagram is shown in Fig.1. It consist of three components

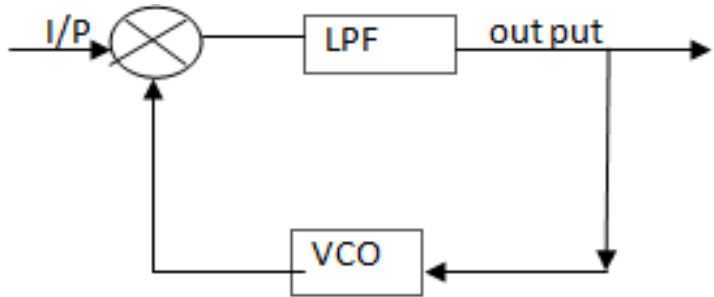

Fig.1 phase locked loop

$>$ A voltage controlled oscillator

$>$ A multiplier serving as a phase detector (or) a phase comparator

$>$ A loop filter which is a low pass filter.

The frequency of VCO can be controlled by the external voltage. In a VCO the oscillation frequency varies linearly with its input voltage. The output of the multiplier is passed through a low pass filter and then applied to the input of the VCO. This voltage then charges the frequency of the VCO and keeps the loop in locked condition. Initially the control voltage to $\mathrm{VCO}$ is zero then is adjusted so that

I) the frequency of the VCO is exactly made equal to the un-modulated carrier frequency $\mathrm{F}_{\mathrm{c}}$;

II) The VCO output has a phase Shift of 90o with respect to the un-modulated carrier wave.

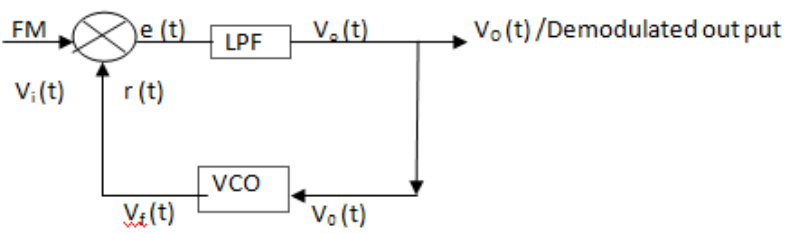

Fig.2

Suppose that the input signal applied to PLL is an FM wave

$$
\mathrm{S}(\mathrm{t})=\mathrm{Ac} \sin [2 \pi f c t+\phi 1(t)]
$$

With a modulating signal $\mathrm{m}(\mathrm{t})$ we have

$\emptyset 1(\mathrm{t})=2 \pi \mathrm{kf} \int_{0}^{\mathrm{t}} \mathrm{m}(\mathrm{t}) \mathrm{d}(\mathrm{t}) \longrightarrow$ eq. 2
If $\mathrm{r}(\mathrm{t})$ denotes the $\mathrm{o} / \mathrm{p}$ of $\mathrm{VCO}$ then

$$
\mathrm{R}(\mathrm{t})=\mathrm{Av} \operatorname{COS}[2 \pi \mathrm{fct}+\emptyset 2(\mathrm{t})] \longrightarrow \mathrm{eq} .3
$$

If $\mathrm{v}(\mathrm{t})$ is the control voltage applied as $\mathrm{i} / \mathrm{p}$ voltage to $\mathrm{VCO}$ then

$$
\varnothing 2(\mathrm{t})=2 \pi \mathrm{kv} \int_{0}^{\mathrm{t}} \mathrm{v}(\mathrm{t}) \mathrm{dt} \longrightarrow \text { eq. } 4
$$

Where $\mathrm{K}_{\mathrm{v}}$ is the frequency sensitivity of VCO and $\mathrm{K}_{\mathrm{v}}$ is measured in $\mathrm{HZ} /$ volt.

The incoming FM wave $\mathrm{s}(\mathrm{t})$ and the $\mathrm{VCO} \mathrm{o} / \mathrm{p}, \mathrm{r}(\mathrm{t})$ are the two inputs to multiplier. The $\mathrm{o} / \mathrm{p}$ e $(\mathrm{t})$ which is $\mathrm{i} / \mathrm{p}$ to the loop filter will be

$$
\mathrm{E}(\mathrm{t})=\mathrm{K}_{\mathrm{m}}[\mathrm{s}(\mathrm{t})][\mathrm{r}(\mathrm{t})] \longrightarrow \mathrm{eq} .5
$$

Where $\mathrm{k}_{\mathrm{m}}$ is multiplier gain

$E(t)=\operatorname{Km}[A c \sin (2 \pi f c t+\emptyset 1(t)][\operatorname{Avcos}(2 \pi f c t+\emptyset 2(t)] \longrightarrow$ eg 6

Now

$$
\begin{aligned}
& E(t)=K m\left[A c A v^{*} 1 / 2[\sin (4 \pi f c t+\emptyset 1(t)+\emptyset 2(t)]+\sin (\emptyset 1(t)-\emptyset 2(t)] \longrightarrow e q 7\right. \\
& =1 / 2 \mathrm{KmAc} A v[\sin (4 \pi f c t+\emptyset 1(t)+\emptyset 2(t)]+\sin (\emptyset 1(t)-\emptyset 2(t)] \longrightarrow e q 8
\end{aligned}
$$

This is the input to the loop filter which is a low pass filter which will attenuate the first term in the above eq. which is high frequency.

$$
\begin{aligned}
\mathrm{E}(\mathrm{t}) & =1 / 2 \mathrm{Km} \text { Ac Av sin }[\emptyset 1(\mathrm{t})-\varnothing 2(\mathrm{t})] \longrightarrow \text { eq. } 9 \\
& =1 / 2 \mathrm{Km} \text { Ac Av sin }[\emptyset \mathrm{e}(\mathrm{t})]
\end{aligned}
$$

Where $\emptyset \mathrm{e}(\mathrm{t})$ is the phase error

$$
\text { Therefore } \varnothing \mathrm{e}(\mathrm{t})=\varnothing 1(\mathrm{t})-2 \longrightarrow \text { eq.10 }
$$

The loop filter operates on its $\mathrm{i} / \mathrm{p}$ e $(\mathrm{t})$ to produce the $\mathrm{o} / \mathrm{p}$ $\mathrm{V}(\mathrm{t})=\int_{-\infty}^{\infty} e(\mathrm{~T}) h(t-\mathrm{T}) d \mathrm{~T} \longrightarrow$ eq.11

Where $h(t)$ is the impulse response of the filter. Substitute $\mathrm{v}(\mathrm{t})$ value in Eq.10

$\varnothing e(\mathrm{t})=\varnothing 1(\mathrm{t})-2 \pi \mathrm{Kv} \int_{0}^{\mathrm{t}} \int_{-\infty}^{\infty} e(\mathrm{~T}) h(t-\mathrm{T}) d \mathrm{~T} \mathrm{dt}$ $\rightarrow$ eq.12

Differentiating eq12 with respect to time

$\mathrm{d} / \mathrm{dt} \emptyset \mathrm{e}(\mathrm{t})=\mathrm{d} / \mathrm{dt} \varnothing 1(\mathrm{t})-2 \pi \mathrm{Km} \mathrm{Kv} \mathrm{Ac} \mathrm{Av} \int_{-\infty}^{\infty} \sin [\varnothing \mathrm{e}(\mathrm{T}) \mathrm{h}(\mathrm{t}-\mathrm{T}) \mathrm{dt} \longrightarrow$ eq.13 Therefore

$\mathrm{d} / \mathrm{dt} \varnothing \mathrm{e}(\mathrm{t})=\mathrm{d} / \mathrm{dt} \emptyset 1(\mathrm{t})-2 \pi \mathrm{Ko} \int_{-\infty}^{\infty} \sin [\varnothing \mathrm{e}(\tau) \mathrm{h}(\mathrm{t}-\tau) \mathrm{dt} \longrightarrow$ eq.14

Where $K_{o}$ is a loop Parameter defined as $K_{o}=K_{M}$ $\mathrm{K}_{\mathrm{v}} \mathrm{A}_{\mathrm{c}} \mathrm{A}_{\mathrm{v}}$

II. NONLINEAR MODEL OF PLL

The equation 14 suggest the nonlinear model as shown in fig 2.This model includes the relationship between $\mathrm{v}(\mathrm{t})$ and $\mathrm{E}(\mathrm{t})$ as represented by eq.9 and eq. 12 this model resembles the block diagram shown in fig.3.the multiplier 
is replaced by subtractor and a sinusoidal nonlinearity, and VCO by an integrator.

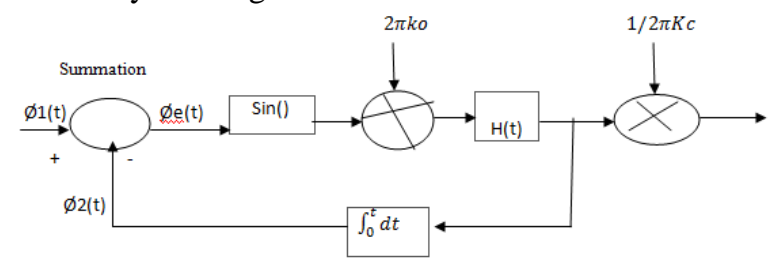

Fig.3 Non-linear model of phase locked loop

\section{LINEAR MODEL OF PHASE LOCKED LOOP}

The phase locked loop is said to be in phase lock when the phase error $\varnothing \mathrm{e}(\mathrm{t})$ is zero when phase error $\varnothing \mathrm{e}(\mathrm{t})$ is less than one radian, we may use the approximation

$\operatorname{Sin}[\emptyset \mathrm{e}(\mathrm{t}) \approx \emptyset \mathrm{e}(\mathrm{t})] \longrightarrow$ eq. 15

The above eq. is accurate to within $4 \%$ for $\emptyset \mathrm{e}(\mathrm{t})$ less than $0.5 \mathrm{rad}$. This approximation tells that we can consider loop near to phase lock when Øe(t) is less than $0.5 \mathrm{rad}$. This approximation allows to disregard the sinusoidal nonlinearity.Thefig. 4 shows the linear model of phase locked loop eliminating sinusoidal non-linearity.

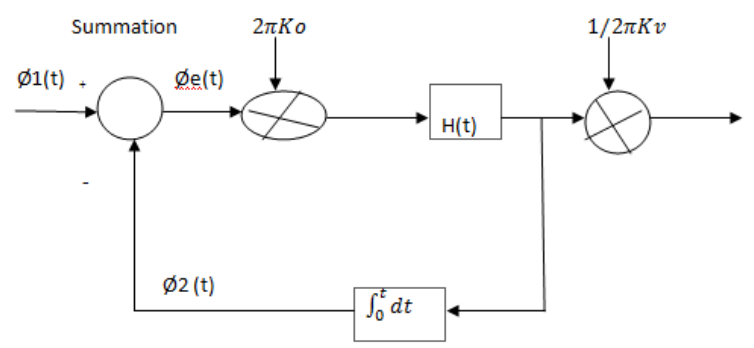

Fig.4 linear model of phase locked loop

From the linear model of phase locked loop we can write

$$
\emptyset 2(\mathrm{t})=2 \pi \mathrm{Kv} \int_{0}^{\mathrm{t}} \mathrm{v}(\mathrm{t}) \mathrm{dt} \longrightarrow \mathrm{eq} .16
$$

We know that

$$
\emptyset_{e}(\mathrm{t})=\emptyset_{1}(\mathrm{t})-\varnothing_{2}(\mathrm{t}) \longrightarrow \text { eq.17 }
$$

Substituting value of $\varnothing 2(t)$ given by the eq.16 ineq.17 we get

$$
\begin{aligned}
& \emptyset_{\mathrm{e}}(\mathrm{t})=\emptyset 1(\mathrm{t})-2 \pi \mathrm{Kv} \int_{0}^{\mathrm{t}} \mathrm{v}(\mathrm{t}) \mathrm{dt} \longrightarrow \mathrm{eq} \cdot 18 \\
& 2 \pi \mathrm{Kv} \int_{0}^{\mathrm{t}} \mathrm{v}(\mathrm{t}) \mathrm{dt}=\emptyset 1(\mathrm{t})-\emptyset_{\mathrm{e}}(\mathrm{t}) \longrightarrow \mathrm{eq} \cdot 19
\end{aligned}
$$

Assuming again small error $\varnothing \mathrm{e}(\mathrm{t})$

$2 \pi \mathrm{Kv} \int_{0}^{\mathrm{t}} \mathrm{v}(\mathrm{t}) \mathrm{dt}=\varnothing 1(\mathrm{t})$

For FM wave input:

$$
\begin{aligned}
& \varnothing 1(\mathrm{t})=2 \pi \mathrm{Kf} \int_{0}^{\mathrm{t}} \mathrm{m}(\mathrm{t}) \mathrm{dt} \longrightarrow \mathrm{kg} .21 \\
& 2 \pi \mathrm{Kv} \int_{0}^{\mathrm{t}} \mathrm{v}(\mathrm{t}) \mathrm{dt}=2 \pi \mathrm{Kf} \int_{0}^{\mathrm{t}} \mathrm{m}(\mathrm{t}) \mathrm{dt}
\end{aligned}
$$

Differentiating both sides with respect to time $t$;

$\mathrm{Kv}[\mathrm{v}(\mathrm{t})]=\mathrm{Kf}[\mathrm{m}(\mathrm{t})]$

$\mathrm{V}(\mathrm{t})$ is directly proportional to $\mathrm{m}(\mathrm{t})$

Thus the $\mathrm{o} / \mathrm{p} \mathrm{v}(\mathrm{t})$ of the low pass loop filter is proportional to the original modulating signal $\mathrm{i}$ or in other Words the input FM signal is demodulated and at the o/p of loop filter, we get the modulating signal.

An interesting feature of PLL, FM demodulator is that the bandwidth of the incoming FM wave can be much wider than that of the loop filter. The baseband of the loop filter has a bandwidth equal to that of the modulating signal i.e. the control signal of the VCO has the bandwidth of the message signal $\mathrm{m}(\mathrm{t})$; but the $\mathrm{VCO} \mathrm{o} / \mathrm{p}$ is a wideband frequency modulated wave whose instantaneous frequency tracks that of the incoming FM wave.

$$
\text { IV.CONCLUSION }
$$

In conclusion firstly the loop filter, VCO and multiplier are investigated of PLL. After investigation multiplier of PLL are replaced by sub tractor and sinusoidal nonlinearity and the VCO by an integrator in non linear model of PLL. If the phase error is less than one radian we may approximation allows disregarding the sinusoidal nonlinearity. The input FM signal is demodulated and at the o/p of loop filter, we get the modulating signal. The baseband of the loop filter has a bandwidth equal to that of the modulating signal i.e. the control signal of the VCO has the bandwidth of the message signal $\mathrm{m}(\mathrm{t})$; but the $\mathrm{VCO} \mathrm{o} / \mathrm{p}$ is a wideband frequency modulated wave whose instantaneous frequency tracks that of the incoming FM wave.

\section{REFERENCES}

[1] F.M. Gardner, "Phase lock Techniques", 2nd Ed. New York: Wiley, 1966.

[2] B. P. Lathi, "Communication Systems", John Wiley and Sons, Inc., 1968.

[3] T.G. Thomas, S. C. Sekhar, "Communication Theory", TataMcGraw Hill 2005.

[4] Haykin, Simon [Ed]. (2001). "Communication Systems", 4th Ed.

[5] Der, Lawrence, Ph.D., "Frequency Modulation (FM)" Tutorial.

[6] A. Blanchard, "Phase Locked Loops", John Wiley \& Sons, 1976.

[7] B. Biwa's, "Range Extension of a Phase Locked Loop". Tran Com., vol. 21, pp. 293, April 1973.

[8] V. Frazier, "Phase Lock Loop Frequency Acquisition Study", Tran. I.R.E., vol. 8, pp. 210, September 1962.

[9] A. V. Bala krishnan, "Advances in Communication Systems", New York: Academic Press, pp. 98-102, 1965.

[10] M. Schwartz, W. R. Bennett, S. Stein, "Communication Systems and Techniques", New York: McGraw-Hill, pp. 161-163, 1966.

[11] C. J. Byrne, "Properties and design of the phase-controlled oscillator with a saw tooth comparator", Bell Syst. Tech. J., vol. 41, pp. 559-602, 1962.

[12] W. C. Lindsey, R. C. Tausworthe, "A survey of phaselocked theory", Conf. Rec. IEEE Int. Commun. Conf., 1967June.

[13] J. J. Stiffler, "On the selection of signals for phase-locked loops", IEEE Trans. Commun. Technol., vol. COM-16, pp. 239-244, Apr. 1968.

[14] F. Carassa, F. Rocca, "Advances in phase-lock demodulation", IEEE Trans. Commun. Technol., vol. COM-18, pp. 182-191, June 1970.

[15] D. P. Olsen, J. C. Lindenlaub, "A phase lock loop with an extended linear range phase detector", Conf. Rec. Mervin J. Kelly Commun. Conf., 1970-Oct.

[16] A. J. Viterbi, "Acquisition and tracking behavior of phaselocked loops", Proc. Symp. Active Networks and Feedback Systems, vol. 10, pp. 583-619, 1960-Apr.

[17] F. D. Natali, W. J. Walbesser, "Interference rejection in a phase-locked loop with decision feedback", EASCON Rec., pp. 187-192, 1968-Sept.

[18] J. C. Schmoock, "A monolithic PLL system for FSK and tone detection", Proc. 7th ASILMOR Conf. Circuits Systems and Computers, 1973-Nov. 